\title{
1 Design of a Novel Multiplex Real Time RT-PCR Assay for SARS-CoV-2 Detection
}

2 Running title: Real time RT-PCR assay for SARS-CoV-2

3 Wei Zhen, Ph.D. ${ }^{1}$, Gregory J. Berry, Ph.D. ${ }^{1,2}$

4

1. Infectious Disease Diagnostics, Northwell Health Laboratories, Lake Success, NY

2. Department of Pathology and Laboratory Medicine, Donald and Barbara Zucker School of Medicine at Hofstra / Northwell

12 Corresponding author:

13 Gregory J. Berry, Ph.D., D(ABMM), Infectious Disease Diagnostics, Northwell Health Laboratories, 450

14 Lakeville Rd., Lake Success, NY 11042

15

16 Phone: 516.224.8506, FAX: 718.224.6585; email: gberry1@northwell.edu 
17

\section{Abstract (limit 250 words):}

Coronavirus Disease 2019 (COVID-19) caused by severe acute respiratory syndrome coronavirus 2 (SARS-CoV-2) has resulted in more than 386,000 deaths globally as of June 4,2020 . In this study, we developed a novel multiplex real time reverse transcription (RT)-PCR test for detection of SARS-CoV-2, with primers designed to amplify a $108 \mathrm{bp}$ target on the spike surface glycoprotein (S gene) of SARS-CoV-

2 and a hydrolysis Taqman probe designed to specifically detect SARS-CoV-2. Following our design, we evaluated the Limit of detection (LOD) and clinical performance of this laboratory-developed test (LDT). A LOD study with inactivated whole virus exhibited equal performance to that seen in the modified CDC assay with a final LOD of $1,301 \pm 13$ genome equivalents/ml for our assay vs $1,249 \pm 14$ genome equivalents/ml for the modified CDC assay. In addition, a clinical evaluation with 270 nasopharyngeal (NP) swab specimens exhibited $98.5 \%$ positive percent agreement and $99.3 \%$ negative percent agreement with the modified CDC assay. The multiplex design of this assay allows the testing of 91 patients per plate, versus a maximum of 29 patients per plate on the modified CDC assay, providing the benefit of testing significantly more patients per run and saving reagents during a time when both of these parameters have been critical. Our results demonstrate that our multiplex assay performs as well as the modified CDC assay, but is more efficient and cost effective and is therefore adequate for use as a diagnostic assay and for epidemiological surveillance and clinical management of SARS-CoV-2. 
Introduction:

Severe acute respiratory syndrome coronavirus 2 (SARS-CoV-2) was first discovered as etiologic agent of Coronavirus Disease 2019 (COVID-19) in the city of Wuhan, Hubei providence, China by the end of December of 2020 (1), and is the seventh coronavirus known to infect humans and also to be transmitted from human to human. The four seasonal coronaviruses (HKU1, NL63, OC43 and 229E) are associated with mild symptoms, whereas SARS-CoV, MERS-CoV and SARS-CoV-2 can cause severe acute respiratory disease $(2,3)$. SARS-CoV-2 belongs to the betacoronavirus genus and is an enveloped, singlestrand RNA virus with a 29.8 kb genome, which can cause a wild range of clinical presentations from asymptomatic or mild illness to fatal outcomes $(4,5)$. Furthermore, the symptoms of COVID-19 patients can be similar to that of patients with other seasonal respiratory infections. Presently, there are no available specific therapeutics or vaccinations against COVID-19, making early and accurate diagnosis for this very contagious disease the key mitigation strategy. specimens have been the standard diagnostic method. To date, the FDA has issued 34 lab developed COVID-19 molecular assays Émergency Use Authorization (EUA) (6). The US CDC has developed the most widely used SARS-CoV-2 assay which includes primers and probes to detect the N1 and N2 regions of the

52 nucleocapsid gene and also the human RNase $P$ gene to monitor RNA extraction and ensure specimen

53 quality (7). For each specimen performed on the modified CDC assay, there are three Master Mix sets,

54 including N1, N2 and RNase P. Each master mix needs to be independently prepared and dispensed into 55 the appropriate wells before the extracted clinical sample RNA is added to each well. The modified CDC 56 assay has been shown to have high analytical sensitivity and ideal clinical performance when compared 57 to three commercially available COVID-19 diagnostic platforms issued EUA status by the FDA (8). 
59 clinical performance of an efficient and cost effective laboratory-developed test (LDT) on the 7500 Fast

60 Dx real time PCR instrument. To that end, we developed an LDT that targets the S gene of SARS-CoV-2 and

61 compared it's clinical performance to the modified CDC assay for the detection of SARS-CoV-2 in

62 nasopharyngeal (NP) specimens from individuals suspected of potentially having COVID-19. 
Primers and probe design: Available whole genome sequence of SARS-CoV-2 (as of February 27, 2020) retrieved from the NCBI GenBank database and the Global Initiative on Sharing All Influenza Database (GISAID) were aligned using Clustal Omega software from EMBL-EBI. The primers and probe were designed using Primer Express 3.0 software in the S gene of SARS-CoV-2 and were synthesized by Integrated DNA Technologies, Inc. (IDT). In addition, the primers and probe of human RNase P gene used for the assay internal control were also synthesized by IDT and were the same sequences used in the CDC assay for this gene target (7). Here, the $5^{\prime}$ base of probe of RNase P gene was modified and labeled with

71 Cy5, and the 3' base of probe was labeled with Black Hole Quencher 2(BHQ2) to allow multiplexing of our 72 LDT assay.

Study design: A modified version (v3) of the CDC assay was used as a reference method in this study (8). A total of 270 NP specimens (130 positive and 140 negative specimens) originally submitted for SARS-CoV2 testing at Northwell Health Laboratories between March and April 2020 were selected for this study. The 270 specimens were initially tested by the modified CDC assay and extracted RNA was stored at $-80^{\circ} \mathrm{C}$ until testing with our LDT was performed. The specimens were selected as any consecutive specimen that was performed on the modified CDC assay during the timeframe of this study and represented our true positivity rate ( $50 \%)$, including positive specimens spanning the range of positivity levels, including 24 specimens with low viral load that characterized by high Cycle threshold $(\mathrm{Ct})$ value in range of 31.7-39.7 by the modified CDC assay. For discordant results, molecular testing was repeated from RNA extraction on both assays. This study was performed in order to validate this LDT for clinical use.

RNA extraction: Total RNA was extracted from $110 \mu$ l of patient NP specimen by the NucliSENS easyMag platform (BioMérieux, Durham, NC) according to the manufacturer's instructions, and the final elution 
volume was $110 \mu \mathrm{l}$. In order to monitor the extraction process, a Negative Extraction Control was included

88 in each extraction run.

Laboratory developed real time RT-PCR assay specific for SARS-CoV-2 detection: In this one-step, primer at $25 \mu \mathrm{M}, 0.72 \mu \mathrm{l}$ of $\mathrm{S}$ gene reverse primer at $25 \mu \mathrm{M}, 0.16 \mu \mathrm{l}$ of S gene probe at $25 \mu \mathrm{M}, 0.64 \mu \mathrm{l}$ of

Analytical Sensitivity (Limit of Detection): Limit of detection (LOD) was determined by extracting and testing serial dilution panels of quantified inactivated SARS-CoV-2 from Isolate USA-WA1/2020 (NR52287, BEI Resources, Manassas, VA) SARS-CoV-2 viral material was provided at a concentration of $4.1 \mathrm{x}$ $10^{\wedge} 9$ genome equivalents $(\mathrm{GE}) / \mathrm{ml}$, from which the following serial dilutions were prepared in $\mathrm{GE} / \mathrm{ml}$ : 4000, 2000, 1000, 500, 250, 125 using Ambion ${ }^{\circledR}$ RNA Storage Solution (Catalog No. AM7001, ThermoFisher

107 Scientific) to prevent the potential RNA degradation, and replicates ranging from 4-10 at each dilution went through nucleic acid extraction on different days and were tested on both the modified CDC assay and our LDT. LOD was defined as the concentration of the lowest dilution that can be detected with 
112 Analytical Specificity: The specificity of our LDT primers and probe for SARS-CoV-2 detection was 113 evaluated by in silico analysis and by testing a SARS-CoV control (GenBanK: MG772933.1) (Cat no. 114 10006624, IDT), MERS-CoV control (GenBank: MK796425.1)(Cat no. 10006623, IDT) and a panel of

115 respiratory pathogens covering Coronavirus (229E, NL63, OC43, HKU1), Influenza A, H3, Influenza B, 2009

116 H1N1, RSV A, RSV B, Parainfluenza virus type 1-4, Human metapneumovirus, Adenovirus, Mycoplasma

117 pneumoniae, and Chlamydia pneumoniae that were initially identified using a multiplex respiratory panel

118 at Northwell Health laboratories.

119

120 Statistical methods: The final result interpretation algorithm for reporting a positive specimen requires

121 both $\mathrm{N} 1$ and N2 targets to be detected in the modified CDC assay (7), and both of the modified CDC assay

122 and our LDT use a $\mathrm{Ct}<40$ as the criterion for positivity. Percent positive agreement (PPA), percent

123 negative agreement (NPA), Kappa, and two-sided (upper/lower) 95\% confidence interval (Cl) were

124 calculated using Microsoft ${ }^{\circledR}$ Office Excel 365 MSO software (Microsoft, Redmond, WA). As a measure of

125 overall agreement, Cohen's kappa values ( $\mathrm{k}$ ) were calculated, with values categorized as follows: $>0.90=$

126 almost perfect, 0.90 to $0.80=$ strong, 0.79 to $0.60=$ moderate, 0.59 to $0.40=$ weak, 0.39 to $0.21=$ minimal,

1270.20 to $0=$ none $(9,10)$. 


\section{Results:}

Design of primers and probe for SARS-CoV-2 detection: Using primer and probe design tool, the assay primers and probe specifically targeting S gene of SARS-CoV-2 (Table 1) were designed to amplify a 108 bp target on the conserved S gene based on multiple sequence alignment and In silico analysis for our LDT primers and probe was performed. The primers and probe designed for $\mathrm{S}$ gene detection were designed using all available SARS-CoV-2 whole genome sequences. Our analysis of sequence alignments revealed that region of the S gene of SARS-CoV-2 targeted by designed primer and probe set have $100 \%$ similarity with all available SARS-CoV-2 whole genome sequence from GenBank and GISAID database at the time of development.

Analytical Sensitivity: Quantified inactivated SARS-CoV-2 virus particles were used to prepare serial dilutions (4,000 GE/mL to 125 genome equivalents $(\mathrm{GE}) / \mathrm{ml}$, in 2-fold dilutions) to determine the LOD of our LDT as well as the modified CDC assay. The LOD was defined as the lowest dilution in which all replicates were detected with $95 \%$ positivity rate by Probit analysis. The LOD of LDT was $1301 \pm 13 \mathrm{GE} / \mathrm{ml}$ for the $\mathrm{S}$ gene target. For the modified CDC assay, the LOD was $1249 \pm 14 \mathrm{GE} / \mathrm{mL}$ for the $\mathrm{N} 1$ target and $946 \pm 11 \mathrm{GE} / \mathrm{ml}$ for the $\mathrm{N} 2$ target (Table 2). The final LOD of modified CDC assay was $1249 \pm 14 \mathrm{GE} / \mathrm{mL}$ in accordance with the result interpretation algorithm.

Analytical specificity: The analytical specificity of our LDT was evaluated using in silico analysis and also by testing a panel of common respiratory viruses, including the four strains of circulating coronaviruses. In silico analysis and Blastn analysis were performed against the standard and betacoronavirus database of National Center for Biotechnology Information (NCBI) and results showed no cross reactivity with other respiratory pathogens; A panel of respiratory pathogens was also tested to further evaluate the specificity 
151 of our LDT. According to our results (Data not shown), a specificity of $100 \%$ was achieved and our LDT had

152 no cross-reaction with any of the pathogens tested.

153

154 Clinical performance: The clinical performance of our LDT was evaluated by comparing to the modified

155 CDC assay. A total of 270 clinical NP specimens from standard of care testing for SARS-CoV-2 on the 156 modified CDC assay from March 2020 to April 2020 at Northwell Health Laboratories were tested. The 157 LDT demonstrated a PPA of $98.5 \%(95 \% \mathrm{Cl}, 0.946-0.996)$, and NPA of $99.3 \%$ (95\% Cl, 0.961-0.999), with 158 the overall percent agreement between both assays being $98.9 \%$. A kappa value of 0.978 ( $95 \% \mathrm{Cl} 0.953-$ 159 1.0) indicated perfect agreement (Table 3). For discordant results from three specimens, two specimens 160 were detected by the modified CDC assay and were not detected by LDT and had a Ct value of 37.3 for $161 \mathrm{~N} 1,39.6$ for N2 and 38.2 for N1 and 39.2 for N2, respectively. Following a fresh RNA extraction and 162 retesting, the specimen with $37.3 \mathrm{~N} 1$ and $39.6 \mathrm{~N} 2 \mathrm{Ct}$ values was detected by both assays, and the other 163 specimen resulted as not detected by both assays. One specimen was initially detected by LDT and not by 164 the modified CDC assay, exhibiting a Ct value of 32.0 on the LDT. After retesting, both the modified CDC 165 assay and the LDT assay were positive. 


\section{Discussion:}

In the present study, a multiplex real time RT-PCR assay was developed and validated for SARSCoV-2 specific detection in NP specimens on the 7500 Fast Dx real time PCR instrument.

The findings demonstrate that our LDT design has comparable clinical performance for the specific detection of SARS-CoV-2 RNA in NP specimens and is more efficient and cost effective in comparison to the modified CDC assay. Our LDT also showed significant advantages over the modified CDC assay, since only one set of primer and probe Master Mix is required to prepare and dispense per specimen, in contrast to three sets of Master Mix preparation and the use of three wells for each patient specimen by the modified CDC assay. Our multiplex design allows us to run 91 patients per plate, versus a maximum of 29 patients per plate on the modified CDC assay. Overall, this allows us to run more than 3 times as many patients per run and also adds to the ease of setting up each run. Additionally, the saving of reagents and consumables is another advantage at a stage where there are currently global shortages of reagents and major assay supply chain issues.

The design of the primers and probe for our LDT is based on multiple sequence alignment of all SARS-CoV-2 genome sequences that were available between January 11 and February 27 of 2020. Since RNA viruses are well known for its high mutation and recombination rates (11), we wanted to confirm that there were no significant new mutations of the region of S gene of SARS-CoV-2 that is the target in our assay that could potentially affect assay performance. To this end, we analyzed an additional 140 SARS-CoV-2 genome sequences uploaded after February 27, 2020 to GenBank and the GISAID database from different countries and performed an alignment with Clustal Omega. This alignment showed that the forward primer and probe are conserved (with 100\% homology) to the $\mathrm{S}$ gene target regions of the SARS-CoV-2 sequences. One exception was seen with the reverse primer, a single base mismatch of S gene target region in one sequence (MT385417.1) from a total of 240 SARS-CoV-2 sequence analyzed both 
189 before and after late Febuary. This one mismatch is questionable, since it is not in keeping with the other

190 sequences available and the databases are not curated, and therefore occasionally contain errors.

191 Limitations of our study include that our LDT is a single site evaluation at Northwell Health

192 Laboratories. In addition, we only use a single target gene for SARS-CoV-2 detection. While there has been

193 a trend toward dual-target design in commercial assay for the detection of pathogens $(8,12)$, occasional

194 monitoring of SARS-CoV-2 sequences to verify that mutations have not developed in the region targeted

195 by our primers and probe is an adequate quality monitor to ensure continued consistent analytical

196 performance.

197 In summary, our LDT has comparable analytical sensitivity and accuracy for specific detection of

198 SARS-CoV-2 RNA when compared to the modified CDC assay. In addition, it also showed superior efficiency

199 and cost-effectiveness and can be somewhat easily-established in other laboratories. These findings make

200 our novel multiplex SARS-CoV-2 assay a suitable alternative for the accurate diagnosis of SARS-CoV-2, with

201 the added benefit of superior efficiency and cost-effectiveness. 
1. Zhou P, Yang XL, Wang XG, Hu B, Zhang L, Zhang W, Si HR, Zhu Y, Li B, Huang CL, Chen HD, Chen J, Luo Y, Guo H, Jiang RD, Liu MQ, Chen Y, Shen XR, Wang X, Zheng XS, Zhao K, Chen QJ, Deng F, Liu LL, Yan B, Zhan FX, Wang YY, Xiao GF, Shi ZL. 2020. A pneumonia outbreak associated with a new coronavirus of probable bat origin. Nature. 579(7798):270-273. https://doi.org/ 10.1038/s41586020-2012-7.

2. Corman VM, Muth D, Niemeyer D, Drosten C. 2018. Hosts and sources of endemic human coronavirus. Adv. Virus Res. 100, 163-188. https://doi.org/10.1016/bs.aivir.2018.01.001.

3. Fauci AS, Lane HC, Redfield RR. 2020. Covid-19 - Navigating the Uncharted. N Engl J Med. 382(13):1268-1269. https://doi.org/10.1056/NEJMe2002387. LJ, Xia ZX, Tan WJ, Cheng GH, Jiang TJ. 2020. Genome Composition and Divergence of the Novel Coronavirus (2019-nCoV) Originating in China. Cell Host Microbe. 27(3):325-328. https://doi.org/10.1016/j.chom.2020.02.001

6. https://www.fda.gov/medical-devices/emergency-situations-medical-devices/emergency-use-

5. Yuen KS, Ye ZW, Fung SY, Chan CP, Jin DY. 2020 Mar 16. SARS-CoV-2 and COVID-19: The most important research questions. Cell Biosci. Published online. https://doi.org/10.1186/s13578-02000404-4 Instructions for Use. https://www.cdc.gov/coronavirus/2019-nCoV/lab/index.html. 
8. Zhen W, Manji R, Smith E, Berry GJ. Comparison of Four Molecular In Vitro Diagnostic Assays for the Detection of SARS-CoV-2 in Nasopharyngeal Specimens. JCM online 27 Apr 2020; DOI: 10.1128/JCM.00743-20.

226

9. Landis JR, Koch GG. 1977. The measurement of observer agreement for categorical data. Biometrics. 33(1):159-174.

228

10. McHugh ML. Interrater reliability: the kappa statistic. 2012. Biochem Med (Zagreb). 22(3):276-2

11. Domingo E and Holland JJ. 1997. RNA virus mutations and fitness for survival. Annu Rev Microbiol. 51: 151-178

20. 
234 Table 1: Real time RT-PCR primer / probe set of S gene target for specific detection of SARS-CoV-2 and 235 primer / probe set of RNase P gene.

\begin{tabular}{|c|c|c|c|}
\hline Target & Name & Sequence $\left(5^{\prime} \text { to } 3^{\prime}\right)^{\text {a }}$ & Vucleotide position \\
\hline \multirow[t]{3}{*}{$\mathrm{S}$} & S Gene-Fwd & TCA ACT CAG GAC TTG TTC TTA C & $21710^{\sim} 21731$ \\
\hline & S Gene-Rev & TGG TAG GAC AGG GTT ATC AAA C & $21796 \sim 21817$ \\
\hline & S Gene-Probe & FAM- TGG TCC CAG AGA CAT GTA TAG CAT-BHQ $1^{\mathrm{b}}$ & 21759 21782 \\
\hline \multirow[t]{3}{*}{ RNase $P$} & RP-Fwd & AGA TTT GGA CCT GCG AGC G & \\
\hline & RP-Rev & GAG CGG CTG TCT CCA CAA GT & \\
\hline & RP-Probe & Cy5-TTC TGA CCT GAA GGC TCT GCG CG-BHQ2 ${ }^{c}$ & \\
\hline \multicolumn{4}{|c|}{${ }^{\mathrm{a}}$ The nucleotide numbering is based on that of the curated SARS-CoV-2 whole genome sequence (GenBank } \\
\hline \multicolumn{4}{|c|}{ accession no. MN908947.3). } \\
\hline \multicolumn{4}{|c|}{ 'The 5' base of S gene -probe was labeled with FAM, and the 3' base of probe was labeled with Black Hole } \\
\hline \multicolumn{4}{|c|}{ Quencher 1(BHQ1). } \\
\hline
\end{tabular}

247 'The 5' base of probe of RNase P gene was labeled with Cy5, and the 3' base of probe was labeled with

248 Black Hole Quencher 2(BHQ2). 
249 Table 2: Summary of limit of detection results

\begin{tabular}{|c|c|c|c|c|c|c|c|c|c|}
\hline \multirow[b]{2}{*}{$\begin{array}{l}\text { Molecular } \\
\text { assay }\end{array}$} & \multirow[b]{2}{*}{ target } & \multicolumn{6}{|c|}{$\begin{array}{l}\text { No. of replicates detected / total no. of replicates at } \\
\text { each dilution expressed by GE } / \mathrm{ml}^{\mathrm{a}} \text { (\% positive rate) }\end{array}$} & \multirow[t]{2}{*}{$\begin{array}{c}\text { Probit } \\
( \pm 95 \% \mathrm{Cl})^{\mathrm{b}} \\
\mathrm{GE} / \mathrm{ml} \\
\end{array}$} & \multirow[t]{2}{*}{$\begin{array}{c}\text { Final LOD } \\
\mathrm{GE} / \mathrm{ml}\end{array}$} \\
\hline & & 4000 & 2000 & 1000 & 500 & 250 & 125 & & \\
\hline $\mathrm{LDT}^{\mathrm{d}}$ & $\mathrm{S}$ & $4 / 4$ & $\begin{array}{c}6 / 6 \\
(100)\end{array}$ & $\begin{array}{l}9 / 10 \\
(90)\end{array}$ & $\begin{array}{l}5 / 10 \\
(50)\end{array}$ & $\begin{array}{l}2 / 8 \\
(25)\end{array}$ & $\begin{array}{l}1 / 8 \\
(25)\end{array}$ & $1301 \pm 13$ & $1301 \pm 13$ \\
\hline Modified & N1 & $4 / 4$ & $\begin{array}{c}6 / 6 \\
(100)\end{array}$ & $\begin{array}{l}9 / 10 \\
(90)\end{array}$ & $\begin{array}{l}7 / 10 \\
(70)\end{array}$ & $\begin{array}{l}6 / 8 \\
(75)\end{array}$ & $\begin{array}{l}1 / 8 \\
(25)\end{array}$ & $1249 \pm 14$ & \multirow{2}{*}{$1249 \pm 14$} \\
\hline CDC assay & N2 & $4 / 4$ & $\begin{array}{c}6 / 6 \\
(100)\end{array}$ & $\begin{array}{l}10 / 10 \\
(100)\end{array}$ & $\begin{array}{l}5 / 10 \\
(50)\end{array}$ & $\begin{array}{l}2 / 8 \\
(25)\end{array}$ & $\begin{array}{l}1 / 8 \\
(25)\end{array}$ & $946 \pm 11$ & \\
\hline
\end{tabular}

$250 \quad{ }^{\mathrm{a}} \mathrm{GE} / \mathrm{ml}$ : genome equivalent/ml.

251 b95\% Cl, upper/lower ( \pm ) 95\% confidence interval.

$252{ }^{\text {' }}$ The final LOD were based on the both assay's results interpretation algorithm and determined by the

253 Probit analysis

254 dLDT: Laboratory developed test. 
bioRxiv preprint doi: https://doi.org/10.1101/2020.06.04.135608; this version posted June 5, 2020. The copyright holder for this preprint (which was not certified by peer review) is the author/funder. All rights reserved. No reuse allowed without permission.

255 Table 3: Clinical performance comparison of between our LDT and modified CDC assay for the detection

256 of SARS-CoV-2 RNA ( $n=270)$

\begin{tabular}{cccccc}
\hline & \multicolumn{2}{c}{ Modified CDC assay } & $\begin{array}{c}\text { Kappa }(\mathrm{k}) \\
( \pm 95 \% \mathrm{Cl})^{\mathrm{a}}\end{array}$ & $\begin{array}{c}\text { PPA } \\
( \pm 95 \% \mathrm{Cl})^{\mathrm{a}}\end{array}$ & $\begin{array}{c}\text { NPA } \\
( \pm 95 \% \mathrm{Cl})^{\mathrm{a}}\end{array}$ \\
\cline { 2 - 5 } LDT & & & & \\
Detected & Not Detected & & 0.978 & $98.5 \%$ & $99.3 \%$ \\
Notected & 128 & 1 & $(0.953-1.0)$ & $(0.946-0.996)$ & $(0.961-0.999)$ \\
\hline
\end{tabular}

257 a95\% $\mathrm{Cl}$, upper/lower ( \pm ) 95\% confidence interval. 